\title{
Spatial Justice: Space, place and counter- normative movement in Latcho Drom
}

\author{
Emma Patchett \\ Käte Hamburger Centre for the Advanced Study of Law and the Humanities, \\ Bonn, Germany \\ Correspondence: Emma.patchett53@law.ac.uk
}

Peer review: This article has been subject to a double blind peer review process

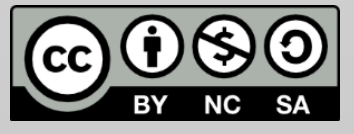

C Copyright: The Authors. This article is issued under the terms of the Creative Commons Attribution NonCommercial Share Alike License, which permits use and redistribution of the work provided that the original author and source are credited, the work is not used for commercial purposes and that any derivative works are made available under the same license terms.

\begin{abstract}
At a time when diasporic identity is being acutely challenged, it is important to pay critical attention to counter-cultural texts which refract hegemonic discourse through alternative spatial landscapes. The French film Latcho Drom (Gatlif, 1993) provides a stylised and radically unique retelling of the journey of the Roma from the Thar Desert in Northern India to Spain, passing through Egypt, Turkey, Romania, Hungary, Slovakia, and France. Gatlif's film can be read as a sensory refraction of legal frameworks of exclusion on the 'edges of Europe', and acts as a site in which it is possible to explore the way in which a minority filmmaker constructs alternative spaces of justice. Through the practice of textual analysis, this article will examine how various framing techniques subvert the hegemonic qualities of the law through the cinematic depiction of a lyrical and diasporic journey through Southern Europe, in order to deconstruct the way in which the aural and visual space refracts law's function as a spacing mechanism. Drawing on Gilles Deleuze's work on cinema and within a theoretical framework of critical space theory, this article will discuss key issues of counter-cultural topographies, alternative spacing mechanisms and the construction of spaces of justice in the context of law and film.
\end{abstract}

Keywords: Law and film; Roma; diaspora; space; temporality; spatial justice

\section{On the Particular Use of Space}

For David Delaney, law operates at every scalar level and in all spaces, and as a consequence there is a need for scholarship which examines the 'contradictions, gaps, slippages in how "law makes space"' (2015: 99100). Using close spatio-legal readings of mise en scène, the cinematographic framing of legalities, and the techniques employed to evoke a distinctive spatio-temporality, this article will offer a distinctive perspective on the way in which Latcho Drom (Gatlif, 1993) resists the normative construction of space. Tony Gatlif's film explores the diasporic 
journey of diasporic Roma from India to Europe, through a series of interconnected musical episodes drawing forth a richly nuanced spatiotemporal framework through which to imagine the potential for spatial justice. The critical act of reading the normative shaping of space through the visual introduces the methodological potential of deconstructing law through film form, focusing on how law is 'framed' through composition, cinematography, colour and how it is represented within the diegesis of the film in a way which subverts the normative shaping of space.' Latcho Drom features cinematic techniques which reflect a critical attempt to see the world, and, in effect, symbolises a method of spatial justice. If law can be regarded as a mode of 'regulation of behaviour [...] controlling the 'use' of a particular space' (Manderson, 2005: 3), the space produced through this film is a central means of examining a subversive process of shaping, interaction and composition, acknowledging that:

a two-dimensional photographic image of projected light and shadow becomes an illusionary, three-dimensional, cinematic landscape. This landscape has its own geography, one that situates the spectator in a cinematic place where space and time are compressed and expanded and where societal ideals, mores, values, and roles may be sustained or subverted. (Hopkins, 1994: 47)

This analysis therefore seeks to explore Gatlif's use of particular techniques in order to subvert normative constructions of space, 'destabilising the frame' (Manderson, 2005: 5) in order to challenge the juridical and socio-political discourse of 'nomadism' as it has historically been employed to justify exclusion and discrimination of the Roma minority (Hancock, 2002; Sigona, 2003, 2005; Simoni, 2011). Taking account of legal constructions of boundaries and limits as 'topoi of the cinematic imagination' (Mendes and Sundholm, 2015: 121), this reading of Latcho Drom will aim to provoke new inquiries into the relationship of law to the visual, beyond the confines of narrative, symbolism and the aesthetic. In this way, reading this film as a counter-narrative has the potential to offer an innovative and important critique of the discourse of nomadism and the ethics of diaspora, revealing the operation of law implicated in the shaping of space (Delaney, 2015: 98). Such counternarratives of spatiality provide an opportunity to cultivate critical awareness of the legal mechanisms producing a monotopic vision of space with problematic consequences, and therefore challenge the normative construction of (legal) space which makes eviction, discrimination and linear definitions of legal occupation possible. In this way, it becomes possible to address the construction of 'illegitimate' subjects within a static national spatial imaginary, as if space never moves whilst the illicit subject moves to cross normative boundaries (Keenan, 2015: 8, 35). This musical narrative filmed in a documentary 
style also evokes a potentially broader discussion about how to position the diasporic subject if the concept of what constitutes 'here' in the context of the cinematic landscape is revealed as a problematic construct which can be both wholly redundant and distinctively revelatory (in unexpected ways) (Massey, 2006: 139).

Tony Gatlif's Latcho Drom (1993) - translated as 'Safe Journey' - can be read as a means of exploring the refraction and subversion of hegemonic discourse in the depiction of a diasporic journey through Southern and Eastern Europe. The film follows communities within the Roma diaspora through moments in their dispersal from India in the 11th century, seeking to trace this series of journeys to Europe through a narrative focusing on the traditions of music which have emerged over time as refrains and melodies which bind this genealogy, running like a thread through multiple communities, timescapes and spatialities. Incorporating scenes which take place in India, North Africa, Turkey, Romania and Hungary, then Italy, France and Spain, Gatlif constructs 'an intensely lyrical portrait of [Roma] culture' (Holden, 1994) through a wordless musical chronology of disparate times, places and events to evoke a story of temporal presence, dispersal and identity.

To address the interweaving threads of temporal space, lyrical echoes and contingent symphonies of this film would require an extensive volume of space in which to fully map out the complex topography Gatlif evokes. Therefore, for reasons of brevity I intend to limit my discussion to three particular 'scenes' or sequences (although perhaps these are better identified as 'locational transitions' or 'moments'). I will be using the work of Gilles Deleuze (1997) on cinema in order to 'think through [the] film' (Herzog, 2001), "i by engaging with his writing on the semiotics of film form (Deleuze, 1997: 365-366). Deleuze's thinking was particularly 'attuned to the specificity of the film image', as a means of unlocking the way in which both the temporal and spatial can be portrayed distinctively in film and, as such, the potential political opportunity for transformation (Herzog, 2001). Deleuze's reflections on cinema can be framed through his central premise, in which he identifies the shift between pre-and post-World War Two cinema, in which linearity and causality were replaced by a non-teleological upheaval in historical and political terms. For Deleuze this resulted in a recognition of the distinction between the 'the time image' (as opposed to the 'movement image') the 'time-image represents a shift from *action* to a focus on *time-in-itself*' (Herzog, 2001). For Deleuze, then, the political impact for what I will term 'spatial justice' rests in the recognition of incommensurability in the interstitial spaces evoked through a particular use of film form. For Deleuze, what made cinema so provocative was the recognition that film represents an operation of provocation, in which spatial and temporal order and 
stratification are depicted in such a way that it is impossible to avoid a challenge to the juridico-political spatial order, even if this is only momentary (Arnott, 2001). In other words, in his two-volume treatise on cinema Deleuze identified distinct modes of film form which reflected different ways of seeing (or 'imaging') the world. Gatlif's film portrays a particular way of seeing that gestures towards spatial justice, as its particular techniques subvert tempo-spatiality and challenge assumptions of static space and nomadic subjects to reveal that, in fact, space itself is 'awkward, angular, unmappable, [and] unpredictable': it is, in this sense, 'not a line defined by two points, but a manifold plane of disorientation and lack of direction' (Philippopoulos-Mihalopoulos, 2010: 204-205). Hence, this non-linear film represents an opportunity to deconstruct the normative shaping of space through the conceptualisation of cinematic spacing and spatiality as a means of exploring the deliberate and implicit dislocation of the illicit subject from the juridico-political spatial order, and subverting this conceit.

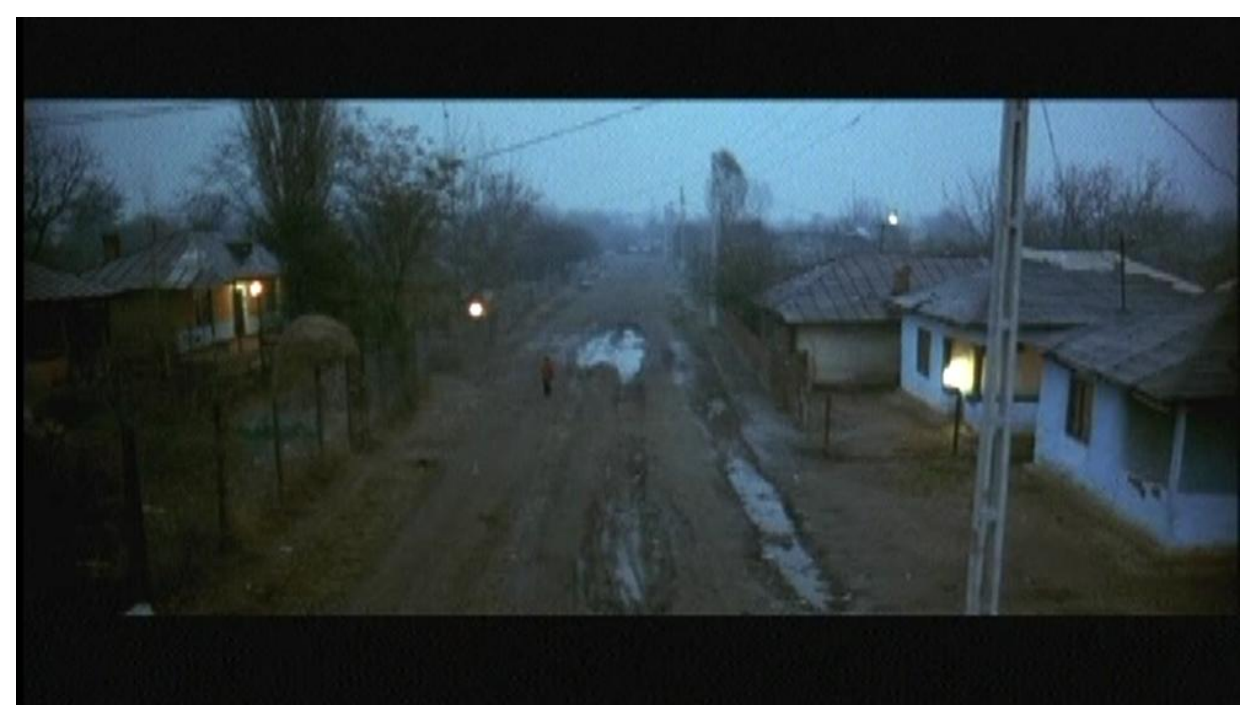

Fig. 1 


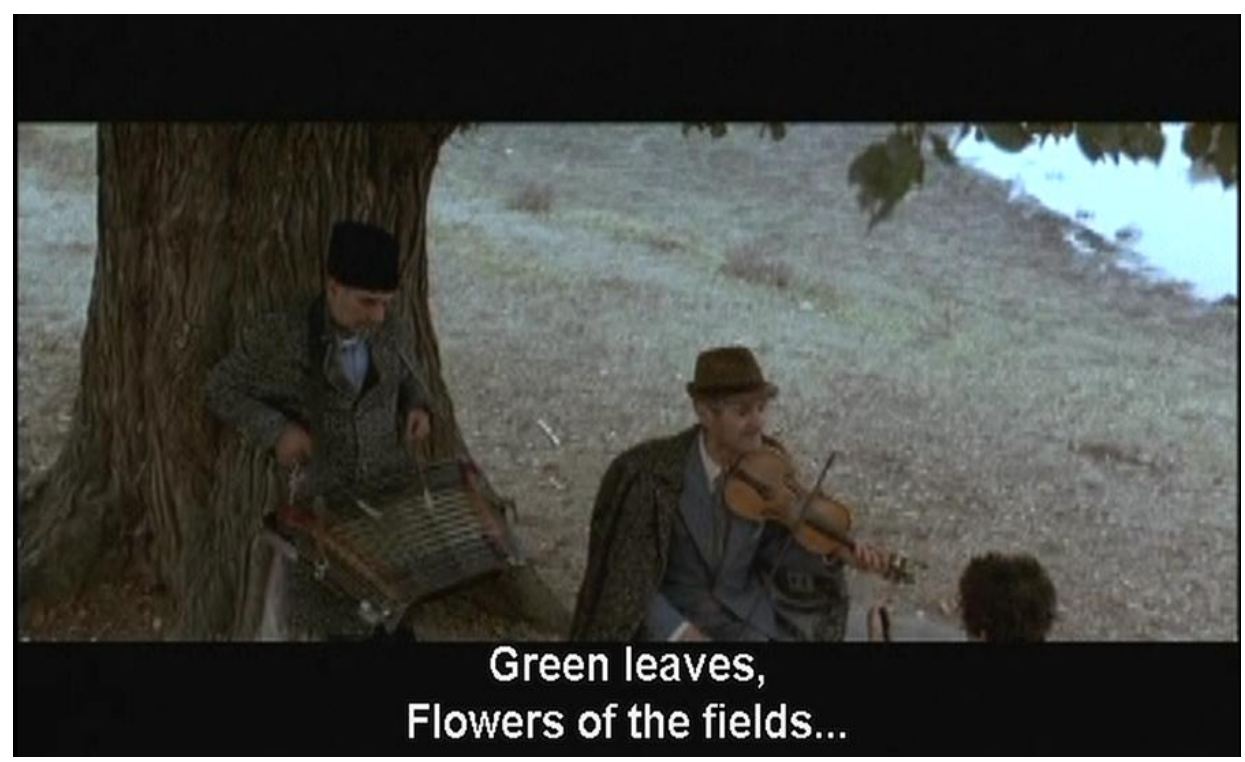

Fig. 2

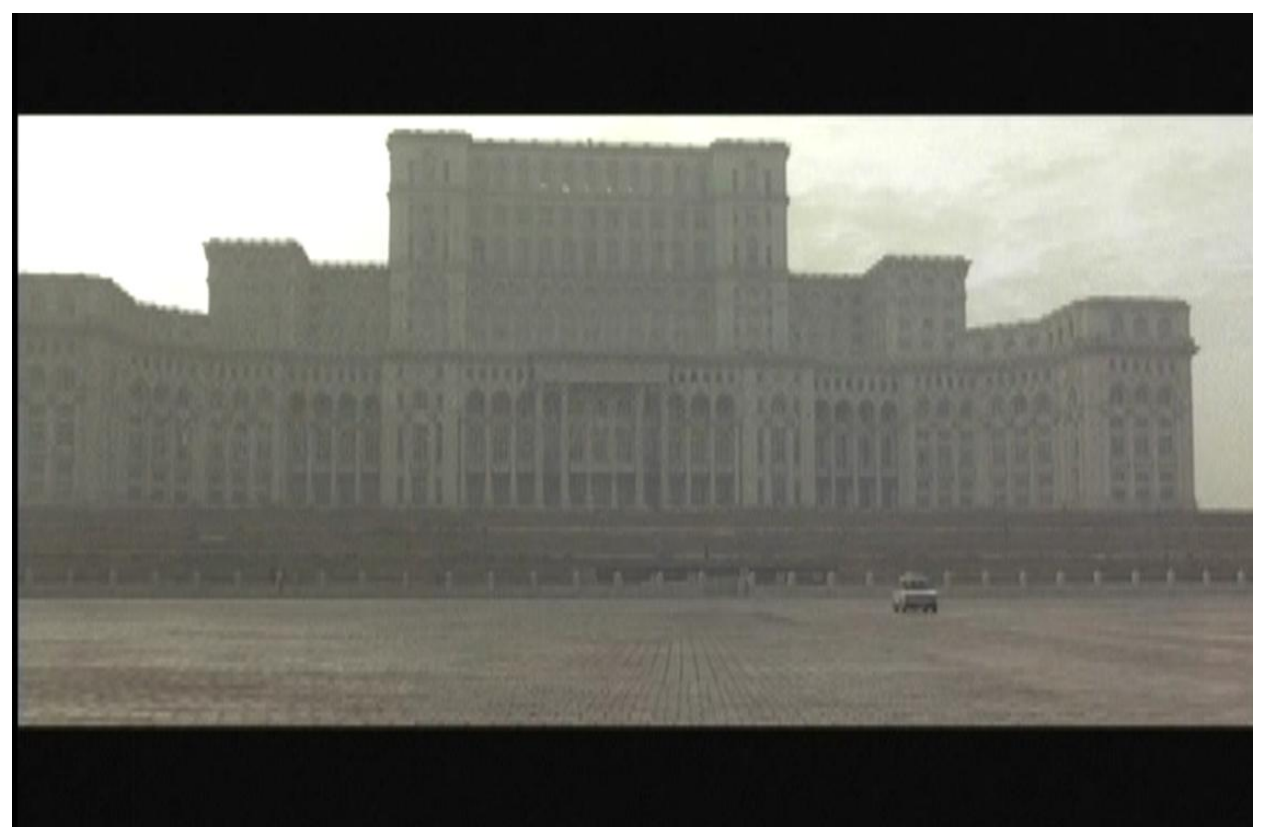

Fig. 3

\section{Place}

The first focal point in this discussion is the locational shift from Turkey to Romania, representing a series of migrations that occurred as part of a broader diasporic journey. Gatlif leads us from one place through another using jump cuts, rather than a fade, to demonstrate ruptures rather than a smooth and fluid transition. Here we see a close-up lowangle shot of the moon, as glimpsed through a telescope on the banks of the Bosphorus Strait, which then immediately cuts to a low angle shot just above ground level of legs splashing through puddles, 
with only the reflection of moonlight in the disturbed puddle a sign of what has gone before [Fig. 1]. The camera cuts to a vantage point above the street, and then proceeds to track down to a medium shot, the boy's footsteps amplified as he walks over to two musicians seated beside a tree [Fig. 2]. Gatlif manoeuvres between close-ups of the boys and the singer as the latter performs, at which point the location is explicitly identified through a song of protest about 'Ceaussescu the Criminal'. The camera zooms in for an extreme close-up, panning back and forth on the singer's hand as he pulls the string of the violin out beside him, holding it taut in order to draw out a haunting, rasping note. As he sings, the camera tilts upwards to a high angle shot buried in the leaves, then cuts to a low angle shot looking up at green leaves cascading from the tree, the sound of the wind a backdrop to the man's haunting song about people 'taking to the streets', the leaves (now brown) scurrying across the ground as the camera pans from right to left. This montage can be said to represent a disruptive impact of discordant cinema and its role in the unravelling of the dogma of spatio-temporal order: here, it represents a particular technique which insists upon sensorial disturbance, in which the aural and the visual are dislodged and diverge from our expectations as a viewer (Arnott, 2001), as evidence of the dynamic operation of both immanent and localised transformations of constitutive elements (Deleuze and Guattari, 1994: 217). Suddenly, we jump to a long, slightly hazy establishing shot of Ceausescu's palace in Bucharest [Fig.3], with the extra-diegetic sound of the protest song enduring throughout the shot. The film cuts to the same boy we had observed listening to the musicians play, indicating a continuity of narrative presence (which is a way Gatlif creates links between different compositional structures). The music stops to indicate another jump cut to the village in which we began, with the same boy moving through the village as the camera tilts from a low angle shot to a vantage point above the rooftops, and then immediately cuts to a close-up of the crisp white sleeve of a man dressing. The vibrant seasonal colours of this scene and the initial introduction to this boy (the red of his jumper, the green of the falling leaves, the yellow houses as the camera tracks the musicians as they step out of their homes) frame the dull browns of the shifting, dead leaves on the ground and cream of the palace exterior. The camera captures the musicians in a medium shot as they are surrounded by a crowd under a clear blue sky, and begin to play. The juxtaposition of this lively, upbeat tempo with the haunting ballad of the previous scene creates a distinctively contrasting topography of sound, with peaks and troughs indicating a rhythm which shifts and changes constantly. The camera takes on the role of numerous spectators in the crowd here, at times tracking through the assembled bodies, sometimes static in an over-the-shoulder shot, and occasionally positioned to capture a low 
angle shot as if the viewer were a child crouching on the ground, gazing up at the musicians as they play. As the song itself gets faster in pace, the camera - although it does cut between close-ups of the musicians and spectators and medium shots of the crowd - stops tracking between them and becomes associated, conversely, with much more static vantage points. This could be said to portray what Deleuze might define as a 'fold', that space 'between interiority and exteriority [which] produces an excess of difference that cannot be contained by the usual ping-pong between self and other', a space which 'keeps on spreading by folding itself' as the 'repeated-taking place, again and again, simultaneously' (Philippopoulos-Mihalopoulos, 2010: 207). For Deleuze, then, '[w]hat counts is [...] the interstice between images, between two images: a spacing which means that each image is plucked from the void and falls back into it' (1997: 179).

\section{Movement}

To understand the potential of Deleuze's conception of cinema for accessing spatial justice it is important to recognise that in his discussion of 'image-movement' he essentially means the 'imagining of movement': hence, '[a]ny time the universe is sliced, we are imaging' (Vitale, 2011). In other words, the image is neither reducible nor subordinate to movement and space but rather directly conceptualises spatial and temporal existence. I want to conflate several 'moments' or distinctive 'scenes' here to explore the aesthetics and thematics of movement (or, to be exact, the 'imaging of movement' as it is depicted in the film). Stephen Holden suggests that the way in which '[t]he songs follow one another [is] like production numbers in a traveling pageant where the landscape and architecture are photographed to suggest giant stage sets. Lingering over full moons, misty fields and centuries-old buildings, the camera paints them as elements of a mystical, ever-changing backdrop' (Holden, 1994). However, following Deleuze, it can be argued that Gatlif does not instil space as a series of reversible screens and painted 'backdrops' before which his characters perform, but rather depicts space 'as the plane of a multiple difference, where lines of orientation run simultaneously in a horizontal vertigo of disorientation', in which, as Andreas Philipoppoulos-Mihalopoulos writes, '[s]pace is not linear but labyrinthine' (2010: 207). 


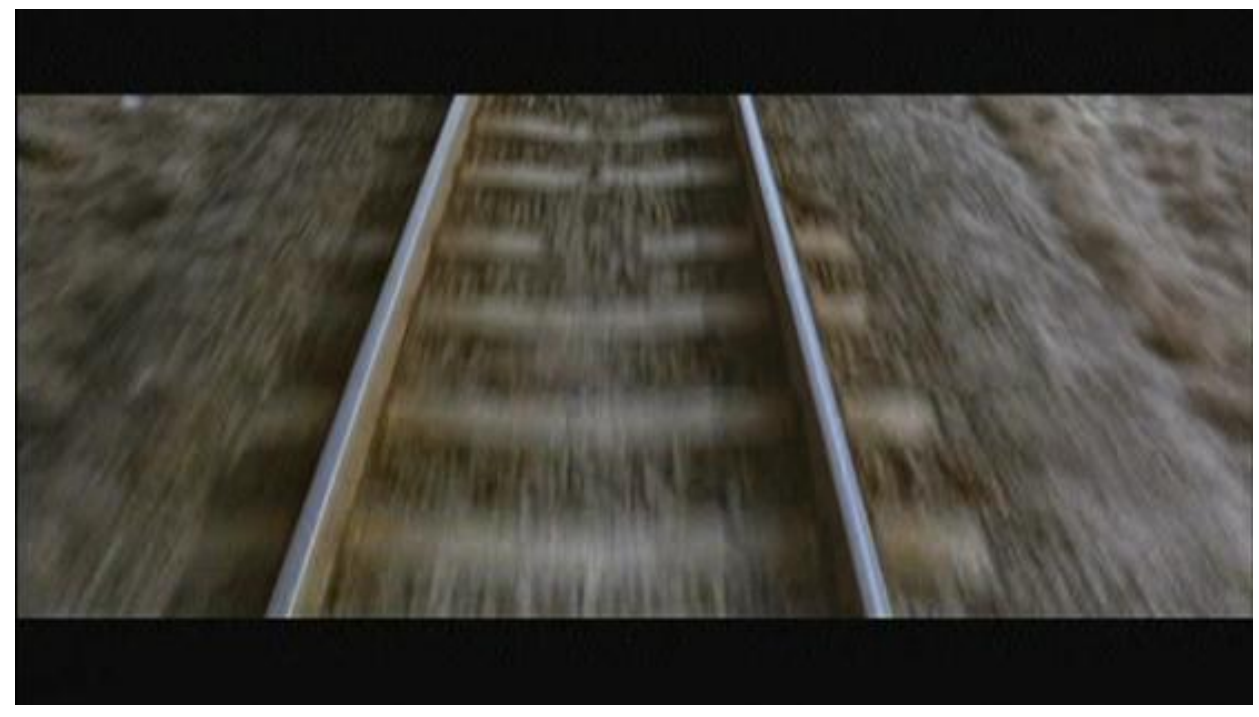

Fig. 4

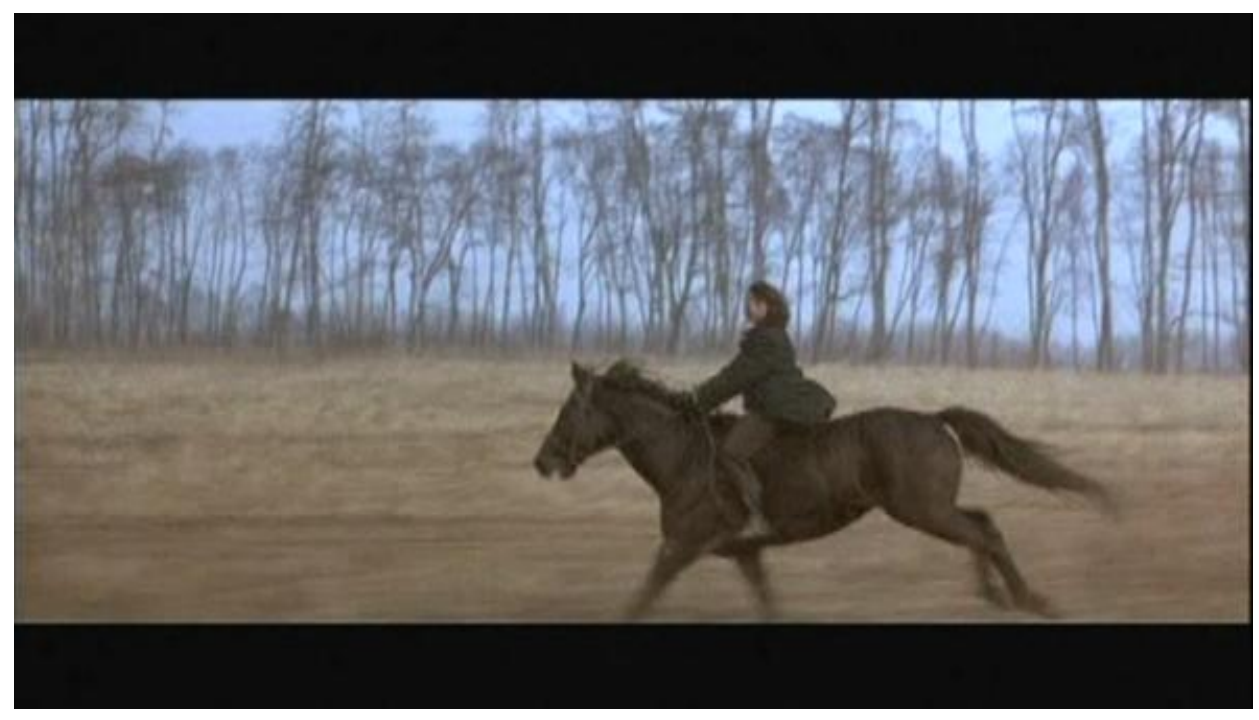

Fig. 5

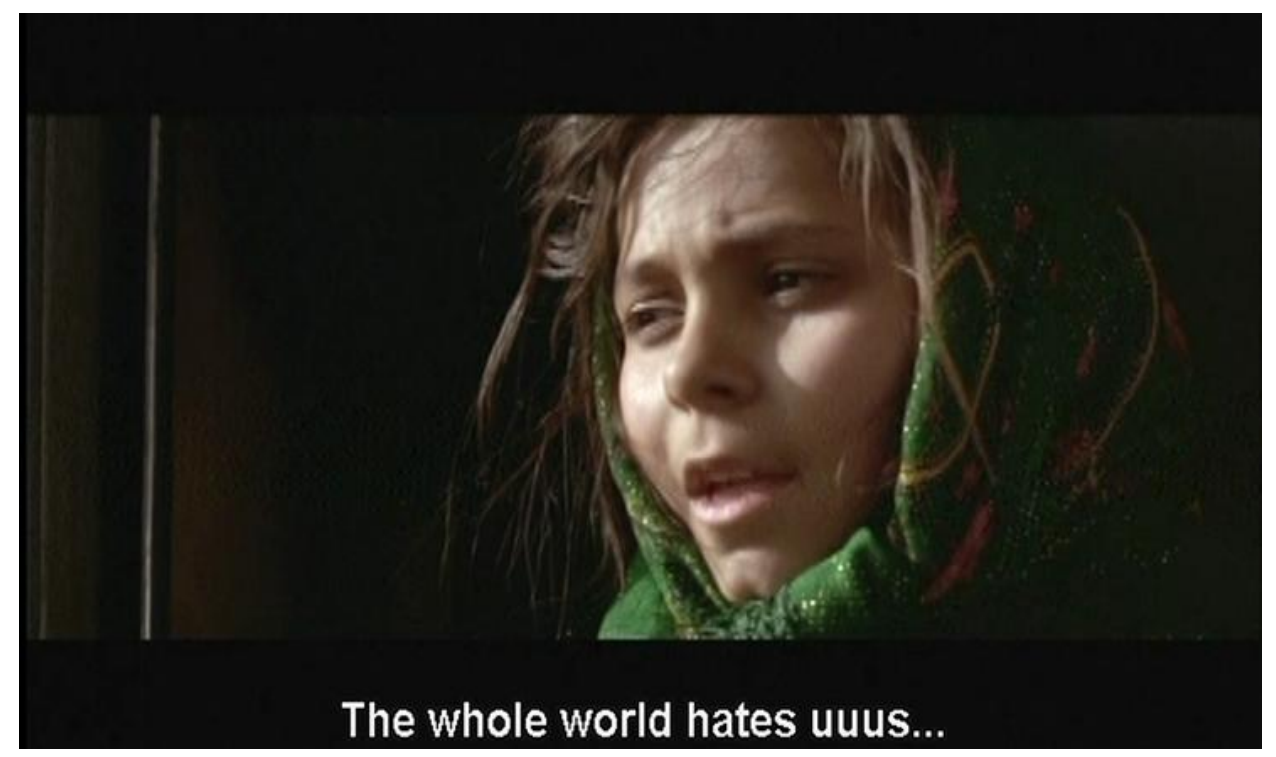


Fig. 6

In the next locational (and, notably, seasonal) shift, the jump cuts create a collage of close-ups of pounding horse's hooves, low angle shots of branches contorted in the wind, tracking shots of the rider and then a close-up of train tracks. These shots, and their accompanying sounds, are all employed to 'drown out' the music from the previous scene, which gradually fades, and emphasise a confluence of motion [Figs 4 and 5]. The audience is then taken immediately inside the train, where a single melody sung by an unaccompanied voice tells the viewer that ' $[t]$ he whole world hates us. We're cursed. Condemned to wandering'. Although the close-up takes us to the subject's face we are never marooned solely inside the train, as exterior shots of the faces at the train window and extreme low angle shots of birds swooping against the wide expanse of blue sky render the space in such a way as to contradict (or at least subvert) the claustrophobia in the cabin and the lyrical space of the song [Fig.6]. The viewer is presented with a common signifier of the fluidity of movement, where as opposed to the jump cut Gatlif employs a close-up of water flowing down-stream, the camera panning along as it ebbs and flows, observing each ripple in turn. The juxtaposition of a mellifluous trickle of water juxtaposed with the harried interruption of abrupt jump cuts and shifts in both time and space is a common motif in this film. Later, we glimpse static shots of caravans in France, expressing movement but restricted to a confined angle in the bottom corner of the screen, behind barbed-wire. One of the 'backdrops' Holden refers to is certainly implicated in another scene in which the camera sweeps in to what appears to be a pastoral scene of horses being washed in the river, their shining coffee-coloured flanks absorbed by a camera which tilts down from the sky and pans across to take in the depth of the scene. We catch a glimpse of a boy's hand as he draws an outline of the horse, engraving their presence onto his own skin. This suggests a unique way in which Gatlif uses space by cutting into it, making both imprints of the echoes of presence and simultaneously (paradoxically) reducing the observer to a static site of restricted access, in which the scene simply unfolds before us. In this scene the viewer is positioned in the dark interior of a caravan, watching over the shoulders of two shadowy backs as two men (presumably landowners, one bearing a gun) come to speak to the group. We never hear what has been said, but the next shot pans across, following the caravans as they depart in a convoy, before stopping to take in the men standing at the edge of the frame. Crucially, the viewer is not positioned above or below the action, behind the men, or in the interior of the caravan. This gives the viewer a peculiar vantage point in which they are seemingly positioned as voyeurs 
but simultaneously disorientated and dislocated: they glimpse neither what has gone nor what will come. Deleuze writes that in film:

[w]e run in fact into a principle of indeterminability, of indiscernibility: we no longer know what is imaginary or real, physical or mental, in the situation, not because they are confused, but because we do not have to know and there is no longer even a place from which to ask. It is as if the real and the imaginary were running after each other, as if each was being reflected in the other, around a point of indiscernibility. (Deleuze, 1997: 7)

This convergence of uncertainty can be seen in the contrast between different points of rupture depicted in the spaces which merge and disassociate from one another in each sequence of the film. In one sequence, Gatlif depicts musicians in their car with a camera mounted on the car bonnet, capturing the speed of the road being swallowed up beneath its wheels. The use of jump cuts emphasises the distance being travelled at high speed, with extra-diegetic music weaving these shots together with the previous scene. Suddenly, Gatlif inserts a video game sequence, a point-of-view shot of a racing game, which we discover is being driven by a boy who will act as a key character in the following sequence [Fig.7]. The music stops, as, off-screen, the boy begins singing a new lament about the life of the 'Gypsy', which then evolves into a quick, restless and ultimately joyous flamenco song.

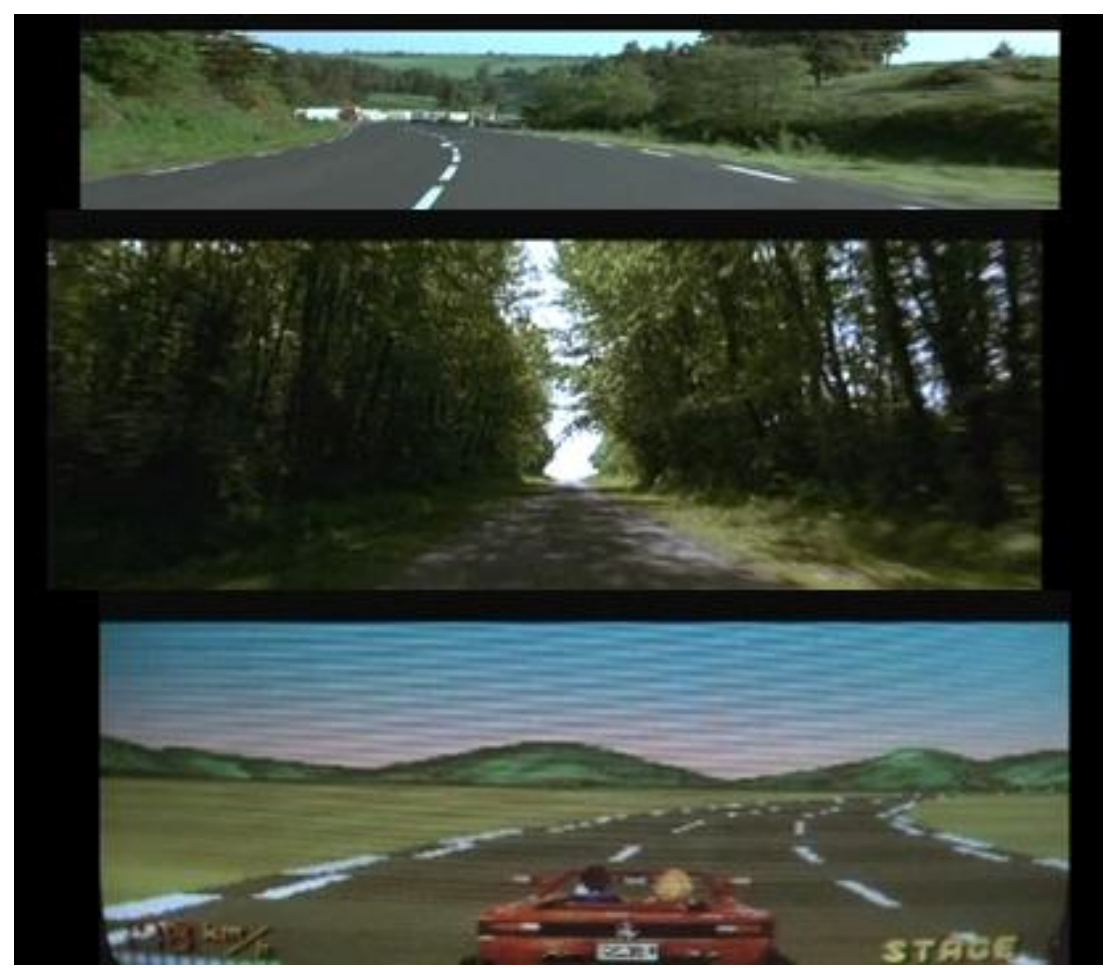

Fig. 7: A composite of stills depicting the driving sequence in Latcho Drom. 


\section{Spatial Justice}

If we think of spatial justice as 'the ultimate expression of the claim to one's unique spatial position' or, in other words, 'the irreducibility of one's corporeal emplacement in space' (Philippopulos-Mihalopoulos, 2010: 202), then Gatlif's subversion of tropes of dislocation can be read as a counter-hegemonic discourse of inhabitation, embodiment and belonging. Those concepts are acutely highlighted in the sequence located in Spain, a sense of place manifested using flamenco rhythms and Spanish dialect in the lyrics of the song. The scene begins with a high angle shot of a public square, and cuts between this perspective and a close-up of the boy singing, and a slight high angle shot of the dancer (wearing the familiar red that has been a motif throughout the film). The echo of this shot reflects an earlier scene in the film, from a North African location, when the camera is positioned from the vantage point of a boy peering down through a window at a crowd watching a woman dance. Here the group is assembled in the open, seemingly embedded in the protective enclave of public space. Gatlif uses a slight low angle shot panning from left to right, interspersed with close-ups of the crowd, to emphasise attentiveness to the dancer, the sound a punctuated cacophony of claps and voices [Fig.8].

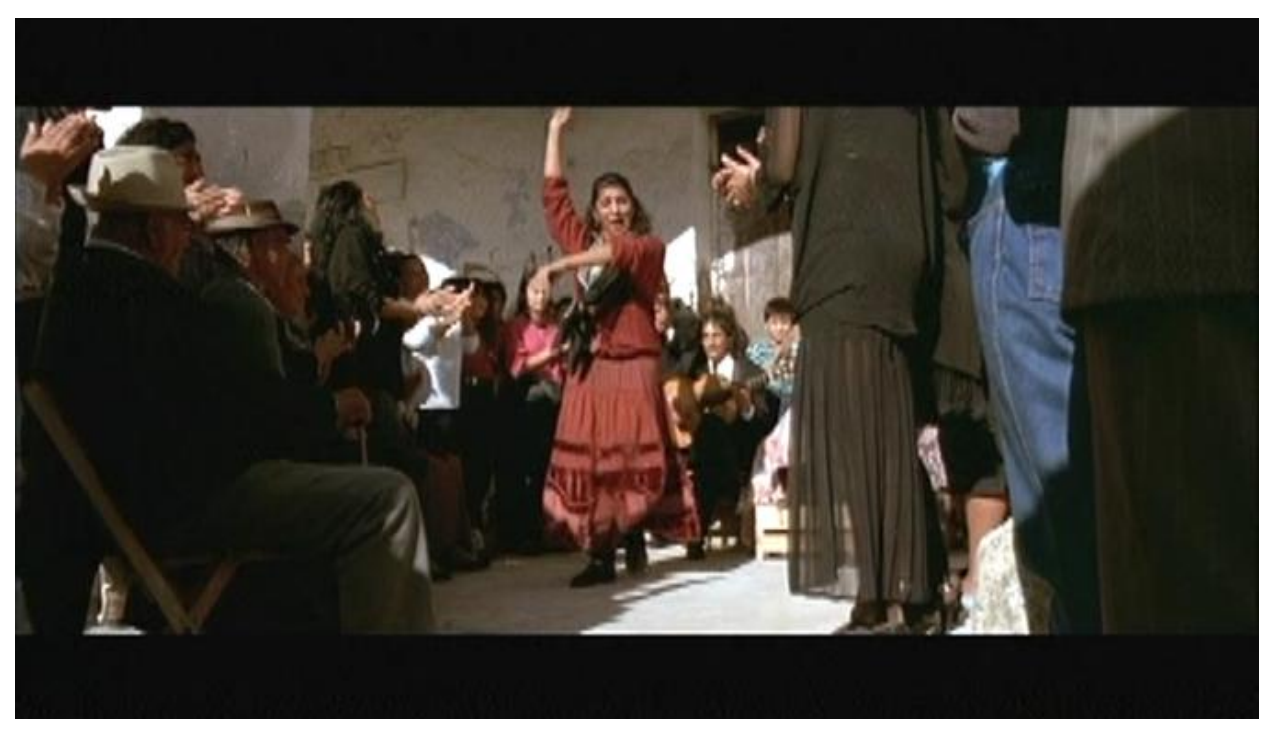

Fig. 8 


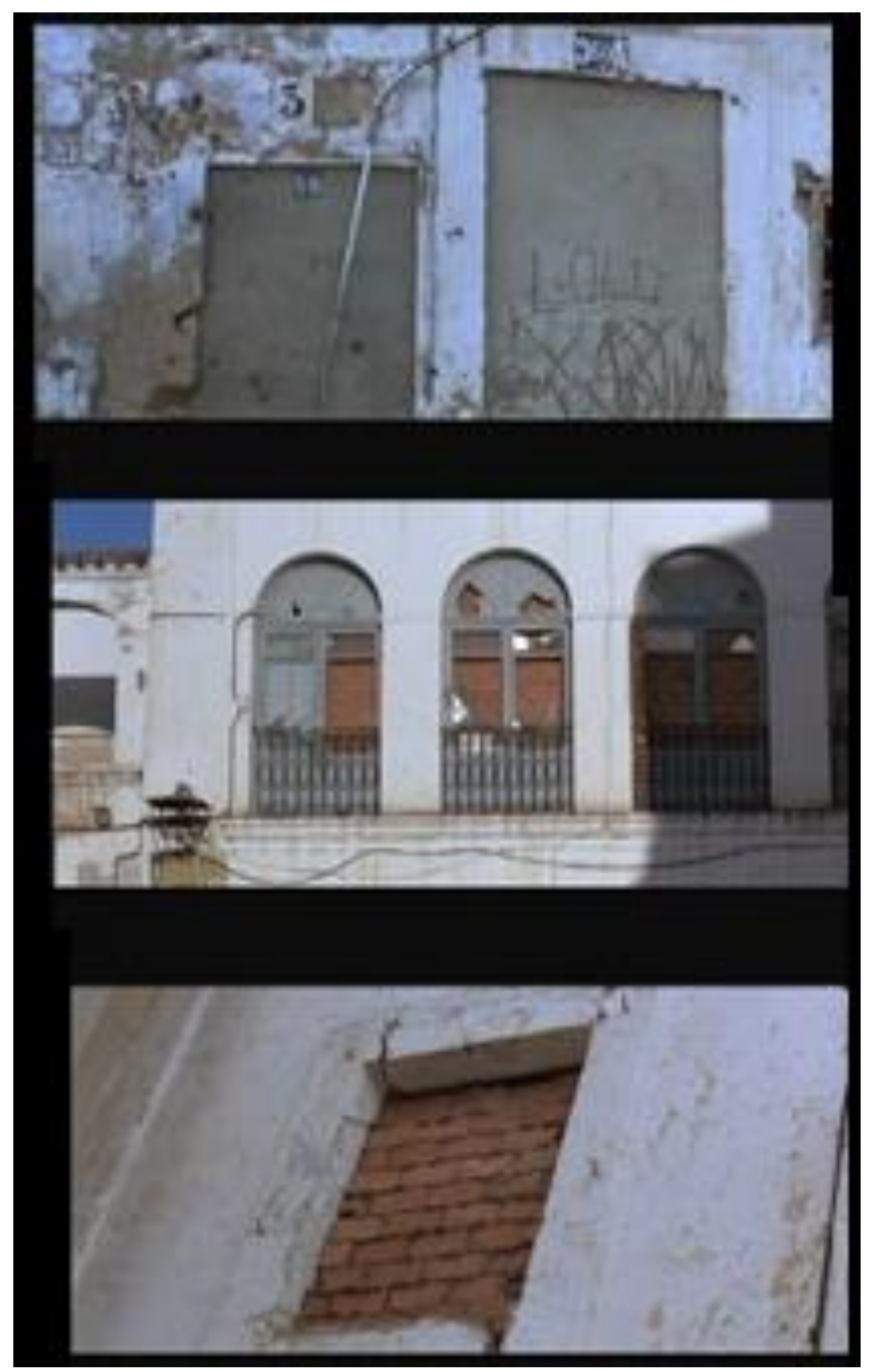

Fig. 9: A composite of stills from toward the end of Latcho Drom.

The dancers are silhouetted by thick orbs of light on the walls, shapes thrown by natural sunshine that resemble the focal circles of spotlights fixedly pointed onto the stage. The song progresses until a jump cut to the mixing of concrete, when, though the music continues, a medium shot of the family going into the square portrays the family being evicted. The extra-diegetic rhythm continues to play as various cutaways depict bricked up windows and peeling, boarded up doors at an increasing pace, whilst the guitars repeat the flamenco refrain [Fig.9]. This montage, echoing earlier similarly jarring sequences in the film, can be read through Deleuze's obsession with the links or connections between images, rather than the images themselves. The repetitions of refrains and reappearance of characters can be considered alongside the use of inserts and jump cuts to create a sense in which we are seeing beyond a purely spatial dimension to the revelation of movement as a uniquely 
temporal perspective (Deleuze, 1997: 22), at the very point at which law (exemplified here in the bricks and boards which attempt to seal the windows and doors) attempts to 'distribute space', as PhilippopoulosMihalopoulos writes:

When the lines conflict and the bodies clash, when a [...] presence is not tolerated, when two peoples are forced to 'share' the same space at the same time [...] there is conflict. Spatial justice is the movement out of this conflict while delving deeper into it. It is the excess whose line of flight returns in the middle, right where it began, in the thick of law. (Philippopoulos-Mihalopoulos, 2015: 211)

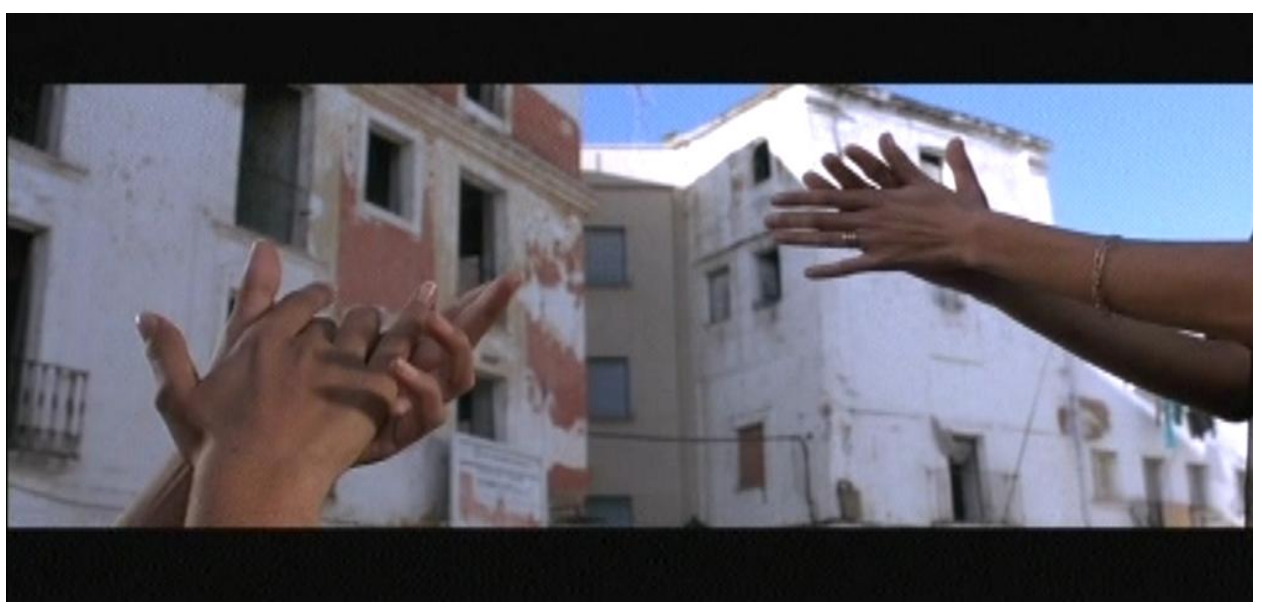

Fig. 10

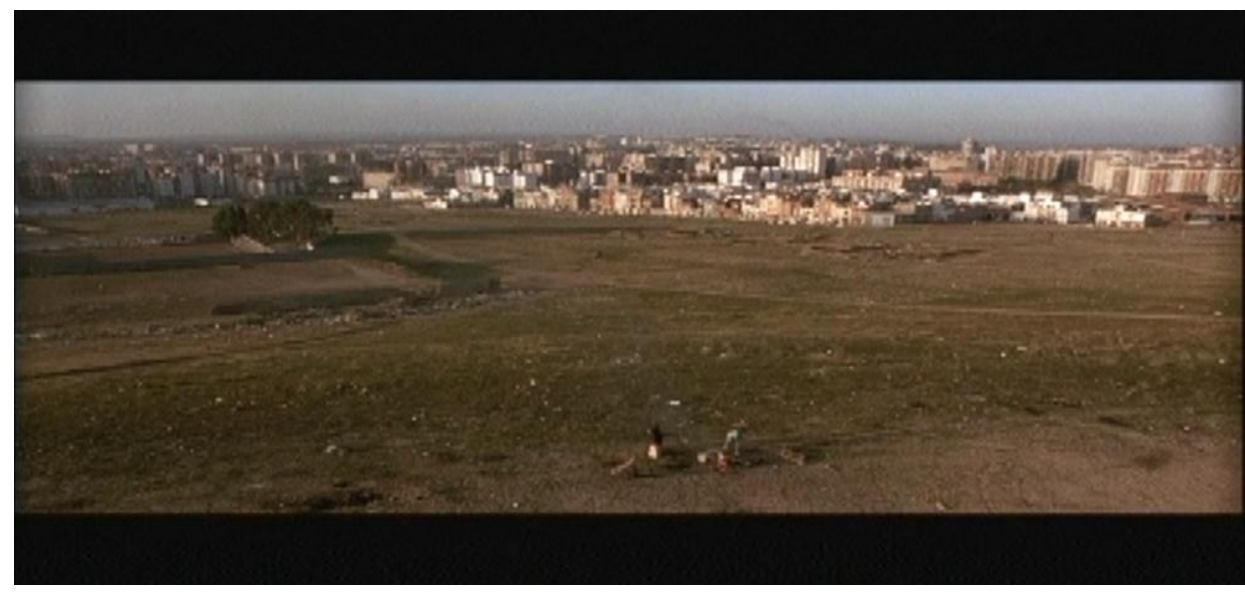

Fig. 11

In the film, the perspective moves to a different location atop a hill, where a wide-angle long range shot pans across the town, juxtaposed with a slight low-angle close-up of a woman (with the same boy we have 
accompanied throughout the scene) singing of her life as 'a black bird who has taken flight'. The camera cuts between her face as she sings, and medium and long shots overlook the town. From within the town, we have shots of disembodied hands clapping long with the rhythm [Fig.10], hands and bodies which reappear on the hillside, flanking a bright blue sky. As in the earlier scenes, fire is used to blur the topography of the town, where orange flames in the foreground crackle in time to the music and provide a focal point which destabilises its clean lines and arterial edges, in contrast to the muted blue and grey tones of the landscape as we pan across the horizon [Fig. 11]. This shallow depth of field is reminiscent of Deleuze's argument that this technique constructs its own temporal horizon that must always feature confrontations between the past and the present; in other words, Latcho Drom reflects the composition of alterity in interaction across, where the temporal is always spatialised by itself (Deleuze, 1997: 108). Instead of depicting this diasporic journey as a distinctly anachronistic dispersal characterised by a linear continuation of excluded culture, this lyrical subversion exposes the ruptures inherent in the unfolding of space implicit in the law. Rather than law drawing the lines of exclusion, these repetitions, discordant juxtapositions and focal distortions represent that even in the shadow of eviction 'law is [always] spacing itself away from space - it turns against its own turning, brutally returning to the banality of the locality, the incantation of the particular and the hasty concealment of a certain fear of space' (Philippopoulos-Mihalopoulos, 2015: 207). The film ends with an upward-moving crane shot in which the boy and woman are foregrounded even as the scale expands, the song continuing until we fade to black. The viewer is abandoned in a temporal space of dislocation, where the image ruptures but not by collapsing in on itself, but by revealing the ever-present closeness of this illicit subject in the foundations of the sensory lawscape. For Deleuze, this rupture denotes a continuous moment of splitting as a recognisable moment of emergence (1997: 81). However, it is important to note that here, this does not leave the viewer with a chronological and nostalgic assertion of historical presence but rather a subversion of spatio-temporality. Rather, Gatlif's use of techniques such as shallow depth of field, jarring montage and extra-diegetic sound represent a depth of the image which is no longer dependent on spatial dimensions, or representations of a chronological continuum of identity in which all we must do is 'observe the journey'. Instead, Gatlif is unravelling a dislocating collection of distal interactions being played out on a temporal lawscape, as a temporal analysis which subordinates both space and movement.

Although this film has been described as a 'messy cinematic tone poem'(Holden, 1994), it can be argued that it is in fact this very 
'messiness' which enables this film to subvert the spatio-legal system, revealing the deconstruction implicit to the normative power of the law's claim to shape space through the evocative film form (Conley, 2001). Reading this film, then, as a gesture towards spatial justice builds on a Deleuzian approach to film as a means of subverting the lawscape by challenging a reliance on the normative positioning of the subject and the bordered construction of space (Deleuze, 1986: 57). Gatlif's film can be read, therefore, as a counter-cultural text 'located in the fold' (Philippopoulos-Mihalopoulos, 2015: 212) which does not define a totality, but reaffirms the emergence of the complex materiality of spatio-temporality (Bruno, 2010: 220). In this way, Latcho Drom insists on reasserting the textures habitually obscured in the assertion of a spatial order, restricting movement, that is authorised through the juridical. Evoking layers of texture through specific techniques demands that the viewer cannot hide from these disturbances of temporality, spatiality and the rendering of place through the illegitimate subject. Gatlif's 'messy' film is a confrontation with materiality that subverts the rhetoric of exclusion and offers the possibility of ongoing deconstruction of the ideological and stylistic 'neatness' of juridical order, as a form of spatial justice (Butler, 2017: 127). Latcho Drom offers us a glimpse of spatial justice in the 'fold' - the tactile leaves rustling along the ground, the assertive cutaways of bricked up windows and the disorientating jump cuts act as various elements which demand that perspective reemerges simultaneously close to the action and, at the same time, at a distance. These sensory distortions and perspectival techniques demonstrate the ways in which Gatlif employs film form to deconstruct law's function as a spacing mechanism through the fold, in which the sensorial impact reflects a gaze at the interstitial non-linear reconstitution of order at its most destabilizing limit (Crockett, 2013: 9597). Playing with a splintered, subversive and immersive juxtaposition of narrative and documentary style, employing extra-diegetic sound and a cyclical chronicle of fractured and fragmented images of a nomadic history that is also always here, in the present, confronts the viewer with the realisation that this portrayal of a diasporic journey does not reify the juridical insistence on a distinction between nomadic outsiders and a singular spatial order, but to celebrate the incommensurability implicit in the normative construction of space. 
'Various significant works exploring the varied relationships between law and film are well-known, for example: Law and Film (Machura and Robson, 2001); Law's Moving Image (Moran et al, 2004); Film and the Law: The Cinema of Justice (Greenfield and Osborn, 2010). Law, Culture and Visual Studies (Wagner and Sherwin, 2014) provides an overview of legal visual semiotics, through a collection of essays which take aesthetic and epistemological approaches to the 'image' in law across multiple disciplines. The essays on film rely on depictions of legality or courtroom scenes in popular culture, rather than a deconstruction of the camera's technique in framing the more fluid aspects of the law. However, the collection provides an excellent variety of case studies in which to draw on 'visual legal meaning making'. Leif Dahlberg (2012) introduces a collection which emphasises law as an aesthetics of visual culture, and takes account of a wide variety of representations in order to consider through the law's visuality through a semiological framework. Some works briefly gesture towards a domain beyond the narrative in law's relationship with film (Black, 1999) whilst others go further to remind us of the impact of film in projecting 'realities' and calls for a renewed focus on the ways in which alternative legal worlds are imagined through film (Sarat, Douglas and Umphrey, 2005). Similarly, Orit Kamir (2006) explores the disciplining practices of what she defines as a 'cinematic jurisprudence' in cross-border cinemascapes to consider how film 'creates' law in the context of gender. My own work draws on the 'film-as-law' perspective which explores how filmic practices shape reality and construct social order with the boldness of legal doctrine (mimicking it, refracting its premises, or enacting a challenging socio-spatial alternative), as can be seen in works such as Law, Film, and Fiction in Contemporary American Culture by Casey Charles (2016) which explores the portrayal of the ideological fictions of law through the queer subject on screen, just as, for example, Alison Young (2005) considers the way the viewer is positioned as judge within an aesthetic framework.

ii Deleuze's work on cinema has been described as 'both taxonomy and history' (Conley, 2001). 


\section{References}

Arnott, Stephen (2001), 'Deleuze's Idea of Cinema', Film Philosophy, 5 (32), http://www.film-philosophy.com/vol5-2001/n32arnott, accessed 3 March 2017

Black, David A. (1999), Law in Film: Resonance and Representation, Chicago: University of Illinois

Bruno, Giuliana (2010), 'Pleats of Matter, Folds of the Soul', in Rodowick, David Norman (ed.), Afterimages of Gilles Deleuze's Film Philosophy, Minneapolis: University of Minnesota Press, pp. 213-34

Butler, Chris (2017), 'Space, politics, justice', in Butler, Chris and Edward Mussawir (eds.), Spaces of Justice: Peripheries, Passages, Appropriations, Abingdon and New York: Routledge, pp.113-30

Charles, Casey (2016), Law, Film, and Fiction in Contemporary American Culture, London: Routledge

Conley, Tom (2001), 'Film Theory 'After' Deleuze', Film Philosophy, 5 (21), http://www.film-philosophy.com/vol5-2001/n31conley, accessed 2 March 2017

Crockett, Clayton (2013), Deleuze Beyond Badiou: Ontology, Multiplicity, and Event, New York: Columbia University Press

Dahlberg, Leif (ed.) (2012), Visualising Law and Authority: Essays on Legal Aesthetics, Berlin: De Gruyter

Delaney, David (2015) 'Legal geography: Constitutitives, complexities, and contingencies', Progress in Human Geography, 39 (1), 96-102

Deleuze, Gilles (1986), Cinema1 - The Movement-Image, Trans. by Hugh Tomlinson and Barbara Habberjam, Minneapolis: University of Minnesota Press

Deleuze, Gilles (1997), Cinema II - The Time-Image, Trans. by Hugh Tomlinson and Robert Galeta, Minneapolis: University of Minnesota Press

Deleuze, Gilles and Félix Guattari (1994), What is Philosophy? Trans. by Hugh Tomlinson and Graham Burchell, New York: Columbia University Press

Greenfield, Steve and Guy Osborn (2010), Film and the Law: The Cinema of Justice ( $2^{\text {nd }}$ edition), Oxford: Hart

Hancock, Ian (2002), We Are the Romani People, Hatfield: University of Hertfordshire Press 
Herzog, Amy (2001), 'Reassessing the Aesthetic: Cinema, Deleuze, and the Art of Thinking', Film Philosophy, Deleuze Special Issue, 5 (40) http://film-philosophy.com/vol5-2001/n40herzog, accessed 1 September 2016

Holden, Stephen (1994), 'Film Review: Gypsies, Dispersed and Despised', The New York Times, 20 July http://www.nytimes.com/movie/review?res=9D0CEED8173EF933A1575 4C0A962958260, accessed 2 March 2016

Hopkins, Jeff (1994), 'A Mapping of Cinematic Places: Icons, ideology, and the Power of (Mis)representation', in Aitken, Stuart and Lo Zonn (eds.), Place, Power, Situation, and Spectacle: A Geography of Film, London: Rowman and Littlefield, pp. 47-65

Kamir, Orit (2006), Framed: Women in Law and Film, Durham NC: Duke University Press

Keenan, Sarah (2015), Subversive Property - Law and the production of spaces of belonging, Abingdon and New York: Routledge

Latcho Drom (1993), directed by Tony Gatlif, France: K.G. Productions Machura, Stefan and Peter Robson (2001), Law and Film, Malden and Oxford: Blackwell

Manderson, Desmond (2005), 'Interstices: new work on legal spaces', Law Text Culture, 9, 1-10

Massey, Doreen (2006), For Space, London: Sage

Mendes, Ana Cristina and John Sundholm (2015), 'Walls and fortresses: borderscapes and the cinematic imaginary', Transnational Cinemas, 6, $117-22$

Moran, Leslie, Emma Sandon, Elena Loizidou and lan Christie (eds.) (2004), Law's Moving Image, London: Routledge

Philippopulos-Mihalopoulos, Andreas (2010), 'Spatial justice: law and the geography of withdrawal', International Journal of Law in Context 6 (3), 201-16

Sarat, Austin, Douglas Lawrence and Martha Umphrey (eds.) (2005), Law on the Screen, Stanford: Stanford University Press

Sigona, Nando (2003), 'How Can a "Nomad" be a "Refugee"? Kosovo Roma and Labelling Policy in Italy', Sociology, 37 (1), 69-79.

Sigona, Nando (2005), 'Locating "The Gypsy Problem". The Roma in Italy: Stereotyping, Labelling and 'Nomad Camps', Journal of Ethnic and Migration Studies, 31 (4), 741-56 
Simoni, Alessandro (2011), 'Roma and Legal Culture: Roots and Old and New Faces of a Complex Equality Issue', European Anti-Discrimination Law Review, 13, 11-15

Vitale, Christopher (2011), 'Guide to Reading Deleuze's The MovementImage, Part I: The Deleuzian Notion of the Image, or Worldslicing as Cinema Beyond the Human', Networkologies, 4 April, https://networkologies.wordpress.com/2011/04/04/the-deleuziannotion-of-the-image-a-slice-of-the-world-or-cinema-beyond-the-human/, accessed 12 June 2015

Wagner, Anne and Richard K. Sherwin (eds.) (2014), Law, Culture and Visual Studies Wagner, Dordrecht: Springer

Young, Alison (2005), Judging the Image: Art, Value, Law, London: Routledge

\section{To cite this article:}

Patchett, E. (2017). Spatial Justice: Space, place and counter-normative movement in Latcho Drom. Exchanges: the Warwick Research Journal, 5(1), 58-76. Retrieved from:

http://exchanges.warwick.ac.uk/index.php/exchanges/article/view/212 